\title{
Retention of Prose Materials as a Function of Postacquisition Testing
}

\author{
Ronald E. LaPorte and James F. Voss \\ University of Pittsburgh
}

\begin{abstract}
One-week prose retention was examined as a function of four activities immediately following reading. Completion questions as an immediate activity with knowledge of results produced significantly better delayed retention than did questions without knowledge of results or presentation of statements equivalent in information to the questions with knowledge of results. These three conditions yielded performance significantly superior to the nonactivity control. Knowledge of results did not increase retention for correctly answered immediate questions, and it signifioantly increased delayed performance for immediate questions incorrectly answered. The immediate activity facilitation findings were attributed to two processes, practice at retrieval of stored information and addition of answers to items not recallable immediately after reading. No delayed retention difference occurred between passage information and equivalent randomly presented statements.
\end{abstract}

The experiment reported in this article was concerned with how delayed retention is influenced by testing or test-related procedures that are employed immediately after reading prose materials. Spitzer (1939) reported that delayed retention was facilitated by immediate testing, a result he interpreted by maintaining that the test trial should be regarded as an additional learning trial which in turn produces superior retention. Subsequently, however, Sones and Stroud (1940) demonstrated that when delayed retention performance is compared between a condition which received a test trial immediately after learning and a condition in which a learning trial was presented in place of a test trial, differential delayed offects were obtained. Specifically, it was

This research was supported by the Learning Research and Development Center, supported in part by funds from the National Institute of Education (NIE), U.S. Department of Health, Education, and Welfare. The opinions expressed do not necessarily reflect the position or policy of NIE, and no official endorsement should be inferred. The research is based upon a master's thesis by R. LaPorte, submitted in partial fulfillment of the master's degree at the University of Pittsburgh.

Request for reprints should be sent to James F. Voss, Department of Psychology, Faculty of Arts and Sciences, University of Pittsburgh, Pittsburgh, Pennsylvania 15620. found that as the interval from reading to immediate testing was increased, delayed retention performance decreased; on the other hand, the effect of an actual additional learning trial upon delayed retention was independent of the interval between reading and the additional learning trial. These findings thus suggested that the learning trial interpretation is not sufficicnt and that further study is needed to determine how the test trial influences delayed retention.

The present experiment was designed to extend the study of the effect of the immediate activity upon delayed recall by varying the nature of the immediate postreading activity. Three experimental conditions were employed, namely, a postreading test trial, a postreading test trial with knowledge of results (KR), and a postreading learning trial. Following the reading of a prose passage, the postreading learning trial consisted of presentation of a series of statements with instructions to learn each statement. The test trial condition consisted of a series of completion questions with each question having the same stem as the respective statement presented on the learning trial. The postreading test trial with knowledge of results containing the same questions, but answers were provided after the subject attempted to answer each question; that is, 
the questions plus the answer provided in knowledge of results were identical to the statements used in the lcarning trial. A control condition was also employed that had no immediate activity. Following cach of these four procedures, subjects were tested by a delayed retention test 1 week later.

In addition to the above manipulation, the present experiment also provided for assessment of the retention of information presented only in the prose passage, information presented only in the immediate activity, and information presented both in the prose passage and during the immodiate activity. The use of procedures which permitted the evaluation of these three types of information presentation represented a departure from previous rescarch because the previous research only permitted comparison of information presented twice (in the prose and the test after reading) with the control in which information was presented only during reading. The particular variation in mode of presentation, that is, passage, immediate activity, or both, had a dual purpose: lirst, it permitted an evaluation of the effect upon delayed retention of information presented only during the immediate activity. Sccond, it permitted the assessment of guessing bohavior during testing.

\section{Method}

\section{Procedure}

Two passages of approximately 1,500 words were used in the experiment. All subjects read one of the passages for $15 \mathrm{~min}$. The subjects were instructed to review the passage if they finished reading before the 15 -min time period was completed. All subjects were able to complete the reading of the passage during the reading period.

Table 1 presents a description of the seven conditions of the experiment. The subjects of the control condition read the passage and were tested only after the delay interval of 1 week. The conditions labeled "Question" received completion questions for the immediate activity, with the correct answer usually consisting of a single word. Knowledge of results was not provided in the Question condition. The conditions labeled "Statement" read the same questions, but the answers were included; that is, a complete statement was presented by presenting the respective completion questions with their answers. The subject made no response in the Statement condition. The Question $K R$ conditions involved presentation of the same completion questions as those of the Question con- dition, and after the subject tried to statc the correct answer, the correct answer was presented. Thus, the information presented in the Statement condition and Question KR condition was identical, but in the latter, subjects had the task of trying to anticipate the correct response. The total presentation time in each condition per question was $15 \mathrm{sec}$.

The three conditions labeled " 50 " (Question 50, Statement 50, and Question KR 50) had 50 factual items in the immediate activity presented as either questions, questions with knowledge of results, or as statements; the three groups labeled " 100 " (Question 100, Statement 100, and Question KR 100) had 100 factual items in the immediate activity. In the 100-item conditions, 50 of the items were relevant (pertaining to the read passage), and 50 of the items were not related to the passage that had just been read. Thus, in the 100 -item conditions, subjects received the same 50 questions on the read passage that the 50 -item conditions received, and they also reccived 50 other questions, statements, or questions with knowledge of results, with this second set of questions being those used for the second, nonread passage. The actual questions and the presentation order of the 50 relevant questions in both the 50- and 100-item conditions were identical, with the only difference being the interspersing of the 50 irrelevant items in the 100-item conditions.

One wcek after reading the assigned passage the subjects returned for delayed testing. The purpose of returning a week later had not been previously discussed. As shown in Table 1, all conditions received 100 questions in Stage 1 of the delayed test. These questions all pertained to the article that was read. The subjects in the control condition thus received 100 questions on the passage that was read. The subjects in the three 50-item conditions were tested with 100 completion questions about the article which was read, with 50 of the items, termed old, being the same as those items presonted in the immediate activity. The other 50 iterns, termed new, were items from the passage that was read, but these 50 items did not appear in the immediate activity. Thus, for the 50-item conditions, it was possible to compare delayed recall for items that had been presented during immediate testing with items that were not presented on the immediate test. Stage 1 of the delayed test for the 100-item conditions consisted of presentation of the same 100 questions presented in delayed recall for the control and the 50 -item conditions. Thus, in the 100-item conditions, delayed retention consisted of presentation of the 50 items related to the read passage that had been presented on the immediate activity and the 50 items of the read passage that had not been presented in the immediate activity.

Stage 2 of the delayed retention test consisted of presentations of another 100 questions for the control and the 100 -item conditions. The questions of Stage 2 pertained to the passage which had not been read. Thus, in the control condition all ques- 
TABLE 1

Description of Experimental Conditions and Procedures

\begin{tabular}{|c|c|c|c|c|}
\hline \multirow{4}{*}{ Condition } & \multicolumn{2}{|c|}{ Immediate activity } & \multicolumn{2}{|c|}{ Delayed test } \\
\hline & \multirow{3}{*}{$\begin{array}{l}\text { No. questions and } \\
\text { statements }\end{array}$} & \multirow{3}{*}{ Passage } & Stage 1 & Stage 2 \\
\hline & & & \multicolumn{2}{|c|}{ No. questions } \\
\hline & & & Read passage & Nonread passage \\
\hline Control & - & - & $\begin{array}{l}100 \\
\text { All new }\end{array}$ & $\stackrel{100}{\text { All new }}$ \\
\hline Question 50 & $50 \mathrm{Q}$ & Read & $\begin{array}{l}100 \\
50 \text { old } \\
50 \text { new }\end{array}$ & - \\
\hline Question 100 & $\begin{array}{l}50 Q \\
50 Q\end{array}$ & $\begin{array}{l}\text { Read } \\
\text { Nonread }\end{array}$ & $\begin{array}{l}100 \\
50 \text { old } \\
50 \text { new }\end{array}$ & $\begin{array}{l}100 \\
50 \text { old } \\
50 \text { new }\end{array}$ \\
\hline Statement 50 & $50 \mathrm{~s}$ & Read & $\begin{array}{l}100 \\
50 \text { old } \\
50 \text { new }\end{array}$ & - \\
\hline Statement 100 & $\begin{array}{l}50 \mathrm{~S} \\
50 \mathrm{~S}\end{array}$ & $\begin{array}{l}\text { Read } \\
\text { Nonread }\end{array}$ & $\begin{array}{l}100 \\
50 \text { old } \\
50 \text { new }\end{array}$ & $\begin{array}{l}100 \\
50 \text { old } \\
60 \text { new }\end{array}$ \\
\hline Question KR 50 & $50 \mathrm{Q} \& \mathrm{KR}$ & Read & $\begin{array}{l}100 \\
50 \text { old } \\
50 \text { new }\end{array}$ & - \\
\hline Question KR 100 & $50 \mathrm{Q} \& \mathrm{KR}$ & Read & $\begin{array}{l}100 \\
50 \text { old } \\
50 \text { new }\end{array}$ & $\begin{array}{l}100 \\
50 \text { old } \\
50 \text { new }\end{array}$ \\
\hline
\end{tabular}

Note, $\mathrm{Q}=$ questions $; \mathrm{S}=$ statements $; \mathrm{KR}=$ knowledge of results.

tions had not been presented in the immediate activity, that is, were new. For the 100 -item conditions, 50 of the Stage 2 questions had been presented in the immediate activity, that is, old, while the other 50 items had not been presented in the immediate activity, that is, new. No knowledge of results was provided during the delayed test.

\section{Materials}

Two long prose passages were initially selected for this experiment. One of the passages was a biography of Sir Issac Newton, and the other passage was on the Watusi tribe in Africa. The passages were reduced so that the information contained within the passage was virtually exhausted by the 100 questions derived from each passage. One half of the subjects in each of the seven conditions received one of the two passages. The immediate activity items of the statements, question, or question with knowledge of results conditions were presented in booklet form with one question or statement appearing on each page of the booklet. For the Question KIR condition, each question was individually presented with the answer presented on the next page. The delayed test questions were also presented in booklet form. The questions were answered on a separate answer sheet, and subjects were carefully monitored to be sure they were following instructions appropriately.

\section{Subjects}

Twenty-four subjects served in each of the seven conditions resulting in a total $N$ of 168 . Approximately eight subjects participated at a time with the order of conditions randomized. The conditions were counterbalanced so that one half of the subjects within each passage condition received one set of 50 questions, and the second half received the remaining 50 questions for the immediate testing on the read passage. The same system of counterbalancing was employed for the nonread passage testing. Two orders of delayed test questions were employed with the orders of 
TABLE 2

Parcentage of Connect Responslis for Tmmedate and Deiayed Testing

\begin{tabular}{|c|c|c|c|c|c|c|}
\hline \multirow{3}{*}{ Condition } & \multicolumn{2}{|c|}{ Immediate test } & \multicolumn{4}{|c|}{ Delayed test } \\
\hline & \multicolumn{2}{|c|}{ Passage } & \multicolumn{2}{|c|}{ Stage 1} & \multicolumn{2}{|c|}{ Stage 2} \\
\hline & Read & Nonread & Old & New & Old & New \\
\hline Control & $\ldots$ & & & $24.04(8.77)$ & & $7.90(2.88)$ \\
\hline Question 50 & $46.08(14.29)$ & & $37.82(15.50)$ & $19.40(10.06)$ & & \\
\hline Question 100 & $56.50(11.30)$ & $4.66(2.61)$ & $48.00(11.35)$ & $24.58(10.25)$ & $8.16(4.94)$ & $6.18(2.94)$ \\
\hline Statement 50 & & & $42.74 \quad(12.18)$ & $21.08(8.46)$ & & \\
\hline Statement 100 & & & $36.40(13.18)$ & $21.24(8.31)$ & $19.66(9.93)$ & $5.32(4.07)$ \\
\hline Question KR 50 & $55.16(12.64)$ & & $56.08(16.86)$ & $23.14(10.56)$ & & \\
\hline $\begin{array}{l}\text { Question KR } 100 \\
M\end{array}$ & $\begin{array}{l}52.74(15.61) \\
51.29\end{array}$ & $3.82(3.11)$ & $\begin{array}{l}48.66(15.88) \\
44.95\end{array}$ & $\begin{array}{l}20.40(10.14) \\
21.64\end{array}$ & $19.74(13.34)$ & $6.66(3.76)$ \\
\hline
\end{tabular}

Note. Standard deviations are given in parentheses.

questions being randomly assigned to half of the subjects within each condition and orthogonal to other conditions.

\section{Results}

Table 2 prosents tho moan percentage of correct responses for immediate and delayed testing performanee of the seven conditions.

\section{Immediate Activity}

Column 1 presents the data for the immediate test questions pertaining to the article which was read. There were, of course, no data gathered in the Statement conditions. The mean of column 1 indicated that approximately $50 \%$ of the questions were answered correctly in immodiate testing as a result of passage reading. An analysis of variance indicated that neither the main effect of number (50 or 100 items in the immediate activity) or presentation mode (questions or questions with knowledge of results) was significant, $F(1,92)=1.00$ and $1.77, p>.05$, respectively. There was, however, a significant interaction of Number $\times$ Mode, $F(1,92)=30.77, p<.01$. (The data of all percentage scores was submitted to an are sin transformation before analysis.) The interaction appoared to be the rosult of subject selection in the Question 50 condition, with three subjects of the Question 50 condition having performed quite poorly. Deletion of the data of these threc subjects resulted in a mean of $52.00 \%$ correct responses for the 50 condition performance.
Column 2 presents the pereentage of correct responses of those questions presented in the immediate activity to the 100item conditions which pertained to the passage that was not read. These data, constituting essentially a guessing cstimate, indicate that recall performance on the nonread passage is not $0 \%$. As indicated, there were approximately $3 \%-4 \%$ correct responses.

\section{Delayed Retention: Stage 1}

Column 3 of Table 2 presents the mean pereentage of correct responses in delayed retention for those 50 questions that had occurred in the immediate test, that is, the old items. $\Lambda$ Dunnett's test revealed that performance on the old items in each of the six experimental conditions was significantly superior to that of the control condition, $p<.01$, in all cases. This result supports previous data indicating that information presented in the passage and in the immediate activity is recalled better than information presented only in the passage (Spitzer, 1939).

The column 3 data of the six experimental conditions were analyzed, with the result that the effect of presentation mode was significant, $F(2,138)=9.46, p<.01$. A subsequent Duncan analysis revealed that performance in the Question KR condition. was significantly supcrior to that of the Question and Statement conditions, $p<.05$, with performance in the latter two conditions 
not significantly different, $p>.05$. Number of questions did not produce a significant effect, $F(1,138)<1.00$, but the numbor variable did interact significantly with presentation mode, $F(2,138)=4.63, p<.05$. Inspection of column 3 data suggests that this interaction is attributable to the fact that the 50-item conditions produced better delayed retention than the 100 -item conditions in the Statement and Question KR conditions, but the reverse held true in the Question condition. The most likely reason for this finding is again the presence of sampling variation in the Question 50 condition. The superior performance in the 50item condition compared to the 100-item condition found in two of the immediate activitios is not particularly surprising, since the occurrenes of 50 questions in the immediate activity that were not related to the passage may have had an interferring effect upon the storage of information from old items during the immodiate activity.

The most important finding of the column 3 analysis is that the Question KR condition produced better delayed retention performance than did tho Question and the Statement conditions. That questions with knowledge of results produced better delayed performance than did questions without knowledge of results is not surprising because the subject received complete question and answer information in the formor but not in the latter condition. The result that is of special interest is the significantly superior performance of the Question KR condition compared to the Statement condition. This finding is noteworthy because it indicates that although the information presented in the immediate activity in both of these conditions was virtually equivalent, the process of trying to retrieve the correct answer found in the Question KR condition yiclded performance superior to that of the Statement condition which involved no such retricval process.

A finer-grain analysis was performed on the old question data by determining the probability of correct delayed recall in the Question and Question KR conditions, given that immediate recall was correct or incorrect. Table 3 presents these data. Column 1
TABLE 3

Probability of Correct Recalat on the Delayed 'Test Given CoRrect on Incorrect Rigchli OF THE SAME QUestron ON THF IMMNDIAT' TEST'

\begin{tabular}{l|c|c}
\hline & \multicolumn{2}{|c}{ Probability of recall } \\
\hline Question & Correct/Incorrect & Correct/Correct \\
\hline & $\begin{array}{c}\text { Delayed- } \\
\text { Immediate }\end{array}$ & $\begin{array}{c}\text { Delayed- } \\
\text { Immediate }\end{array}$ \\
\hline 50 & .73 & .07 \\
100 & .81 & .06 \\
KR 50 & .78 & .30 \\
KR 100 & .72 & .28 \\
\hline
\end{tabular}

(Table 3) presents the probability of correct delayed recall, given that the response to the particular question was correct at immodiate recall. Analysis revealed no significant difference in the Question and Question KR conditions on this measure, $F(1,92)<1.00$. Number of questions in the immediate activity also did not yicld a significant effect, $F(1,92)<1.00$. The interaction of the two variables was, however, significant, $F(1,92)$ $=8.66, p<.01$. Again, the finding that the Question KR 50 condition produced better conditional probability performance than the Question KR 100 condition is not surprising because of the occurrence of the 50 irrelevant questions in immediate activity in the KR 100 condition. There is, however, no apparent reason other than sampling variation for the difference in performance of the Question 50 and Question 100 conditions. In any event, the most important aspect of the analysis is that no reasonable evidence was found to support the hypothesis that the Question KR condition yiclded performance significantly superior to tho Question condition with respect to correct delayed recall, given that the respective item was corroctly recalled at the immediate test.

Column 2 (Table 3) presents the probability of a correct response in delayed recall, given that the response to the particular question was not correct in the immediate activity. As shown, the Question KR condition produced substantially better delayed recall performance than did the Question-only condition on this measure, 
$F(1,92)=89.15, p<.01$. Neither the number of question variable nor the interaction of number of questions with the two experimental conditions is significant, $F(1,92)<$ 1.00 , in both cases. Thus, the Table 3 data indicate that the facilitative effect of the Question KR immediate activity compared to the question without knowledge of results immediate activity is attributable to the occurrence of a greater increase in correct responses for those questions the subject had not gotten correct in the immediate recall. Also, the data indicate the rather interesting point that the immediate activity of the Question KR condition did not reduce forgetting significantly more than did the Question condition for those questions which the subject had gotten correct in the immediate activity. In other words, the immediate activity of the Question KR condition did not make the correct responses more resistant to forgetting than did the immediate activity of the Question condition.

Returning to the data of Table 2 , the column 4 data were analyzed in order to determine whether the presentation mode and number of question manipulations for the immediate activity produced any delayed retention effects upon the performance of the new questions, that is, those questions on the read passage that were not prosented in the immediate activity. A Dunnett analysis revealed that the performance of each of the six experimental conditions did not differ significantly from that of the control, $p>$ .05 , in all cases. The performanee of the six experimental conditions also was submitted to analysis, with the result of no significant difference of presentation mode, $F(2,138)<$ 1.00 ; number of questions, $F(1,138)<1.00$; and the interaction of the two variables, $F(2,138)=2.21, p>.05$. Thus, the analyses of the column 4 data indicate that the type of immediate activity did not significantly influence delayed retention for the questions that were asked for the first time on the delayed retention test. This result indicates that the immediate activity, while significantly influeneing delayed recall for items presented in the immediate activity (column 3), produces no significant effect upon delayed retention for questions only presented at delayed recall. This is a note- worthy negative result since it strongly suggests that any effects of immediate testing are item or question specific and the facilitation in performance that occurs in delayed retention as a function of the immediate activity is not a general effect.

\section{Delayed Retention: Stage 2}

As noted in Table 1, Stage 2 of the delayed retention test included 50 questions from the nonread passage that were presented in the immediate activity of the three 100 -item conditions, the old questions of the nonread passage, as woll as 50 questions from the nonread passage that were not presented in the immediate activity, that is, new questions. Column 5 of Table 2 presents the percentage of correct delayed recall responses of the information presented exclusively in the immediate activity and not in the passage, and column 6 presents the percentage of correct new questions given in delayed recall for the unread passage, but not presented in the immediate activity. Two results of the column 5 and column 6 data may be noted. First, to no surprise, the Statement and the Question KR conditions yielded superior performance to the Question condition for the column 5 data, and little difference was shown in column 5 data in the performance of the Question KR and Statement conditions. Second, performance on the old questions in the Question condition (column 5) did not differ significantly from that of the control condition, $t(91)=.09, p>.05, \mathrm{a}$ result simply indicating that presentation of the questions without the answers in the immediate activity did not facilitate retention, a not surprising result (see Table 2).

An interesting comparison that may be made is between the delayed retention data of columns 4 and 5 (Table 2) for the Statements and Question KR 100 conditions. In essence, this comparison is between the retention of information presented only in the passage and not in the immediate activity (column 4) to information presented only in the immediate activity and not in the passage (column 5). Analysis of variance revealed that for the Statements and the Question KR conditions, there is no significant difference in performance in recall between the material presented only in the 
passage and the material presented only in the immediate activity, $F(1,207)<1.00$.

\section{Discussion}

The results of the present experiment support four conclusions regarding the effect of the immediate activity upon delayed retention performance. First, the findings indicated that all immediate activity conditions of the prosent experiment facilitated delayed retention. Second, the results indicated that such effects are question or information specific in that only retention of the passage information presented in the immediate activity was shown to produce facilitation in delayed retention; passage information tested at delayed retention which involved information not presented in the immediate activity yielded no better performance than that of the control condition. Thus, the facilitative effect of the immediate activity upon delayed retention is specific to the information of the immediate activity. Third, although delayed retention in each of the six experimental conditions was superior to that found in the control condition, the magnitude of the facilitation varied with the experimental condition. Specifically, asking questions and providing knowledge of results produced better delayed retention than did either questions without knowledge of results or the presentation of statements which were essentially equivalent in information content to the Question KR condition. Furthermore, the conditional probability data of Table 3 indicate that the superior performance of the Qucstion KR condition to the Question only condition was primarily due to the occurrence of correct responses in delayed retention to questions that were not responded to correctly in the immediate testing, but was not attributable to reduced forgetting in delayed retention of those questions which were responded to correctly. This third conclusion requires special consideration.

The issue of why the Question KR condition produced better delayed retention performance than did the Question only condition may be explained by the conditional probability data of Table 3 , as mentioned above, but the matter of why the Question $\mathrm{KR}$ condition yielded superior performance to that of the Statements condition is of special interest. This result may be interpreted as supporting the view that the process of retriving information per se has a facilitative effect upon delayed retention of that information. More specifically, the three experimental conditions may be viewed in the following way. Performance in the Statements condition was superior to that of the control condition, because the information provided in the immediate activity increased the likelihood of retention of specific information in the statements, and quite conceivably, the Statements condition thus gave the subject knowledge of some information he would not have been able to recall at the time of the immediate activity. The Question condition produced better delayed recall than did the control condition not because any now information was presented but because the subject had practice at retricving the information he knew. The Question KR condition had both benefits, however. It provided the subject with correct information when he was not able to respond correctly, and it provided practice at retrieving the information he was able to state in the immediate activity. Thus, this explanation postulates the operation of two factors of immediate activity that act to facilitate delayed retention, namely, the gain of correct response information at immediate testing (the Statement and Question KR conditions) and the facilitation which occurs that is attributable to retrieving correct responses (the Question and Question IRR conditions). In agreement with this explanation is the fact that facilitation of retricval of correct information upon the delayed subsequent retrieval of the same information has been reported by Allen, Mahler, and Estes (1969) and Hogan and Kintsch (1971).

The fourth conclusion of the present experiment must be regarded as highly tentative, but nevertheless of theoretical intercst. The results indicated that there was no significant difference in delayed retention performance for the material that was presented in the passage or at immodiate testing. This result is of interest for it indicates that the presentation of the information cmbedded in an organized passage structure produced no better delayed retention than did the pres- 
entation of 50 discrete statements cmbedded in 50 statements pertaining to another passage. In other words, passage organization did not facilitate retention. This finding, clearly contrary to a number of views on the role of organization in memory (ef. Tulving $\&$ Donaldson, 1972), must be regarded as highly tentative however, because of the nature of the passages used and the nature of the testing employed. The passage was constructed so that it essentially contained only 100 statements that were to bo used in testing and as such may have involved a reduction in organization. Yct, the finding is somewhat surprising.

\section{REFIRENCES}

Allan, G. A., Mahler, W. A., \& Estes, W. K. Wffects of recall tests on long-term retention of paired associates. Journal of Verbal Learning and Verbal Behavior, 1969, 8, 463-471.

Hogan, R. M., \& Kintsch, W. Differential effects of study and test trials on long-term recognition and recall. Journal of Verbal searning and Verbal Behavior, 1971, 10, 562-567.

Sones, A. M., \& Stroud, S. B. Review with special reference to temporal position. Journal of Educational Psychology, 1940, 81, 665-676.

Spitzer, H. F. Studies in retention. Journal of Educational Psychology, 1939, 30, 641-657.

Tulving, E., \& Donaldson, W. Organization of memory. New York: Academic Press, 1972.

(Received June 4, 1974)

\section{Manuscripts Accepted for Publication in the}

\section{Journal of Educational Psychology}

A Typology of University Student living Groups. Rudolf II. Moss (Department of Psychiatry, Stanford University Medical Center, Stanford, California 94305), Bernice Van Dort, Penny Smail, and Alan J. DeYoung.

Preforence-Success Assumption in Education. Thomas N. Dorsel, (1)epartment of Psy. chology, School of Education and Psychology, Western Carolina University, Cullowhee, North Carolina 28723).

Memory for a Tecture: liffects of Notes, lecture Rate, and Informational Density. Edwin G. Aiken (Program Director, Training and Hducation Systems Directorate, Department of the Navy, Navy Personnel IResearch and Development Center, San Diego, California 92152), Gary S. Thomas, and William A. Shennum.

Effects of Active Training upon Conjunetive Concept Attainment in Children. Jeanette Gallagher (Department of Vducational Psychology, Temple University, College of Education, Philadelphia, Pennsylvania 19122) and I). Kim Reid.

Word Recognition Cues Used in Matehing Verbal Stimuli Within and Between Auditory and Visual Modalities. Ingrid Swensen (College of Iiducation, Arizona State University, Tempe, Arizona 85281).

Effect of Teacher Sex, Student Sex, and Teacher Warmth on the Evaluation of College Instructors. Patricia B. Holmore (Guidance and Educational Psychology Department, Southern Illinois University, Testing Center, Carbondale, Illinois 62901) and Karen $\Lambda$. La Pointe.

Paired-Associate and Serial Learning in Retarded Readers. Bonnie W. Camp (University of Colorado, Medical Center, 4200 East Ninth Avenue, Denver, Colorado 80220) and Nancy W. Dahlem.

Convergent and Discriminant Validation of Three Classroom Observation Systems: $\Lambda$ Proposed Model. (Xary D. Borich (Research and Development Center for Teacher Education, University of Texas, Austin, Texas 78712) and David Malitz.

Persistence, Achievement, and Open Space linvironments. Steven Reiss (Department of Psychology, University of Chicago at Chicago Circle, Box 4348, Chicago, Illinois 60680) and Nester Dyhdale.

Instructional Treatments, Presenter Types, and Learner Characteristics as Significant Variants in Instructional Television for Adults. Robert I). Brown (I )epartment of liducational Psychology and Measurements, Teachers College, University of Nebraska, Lincoln, Nebraska 68508), Lawrence A. Brown, and James F. Danielson.

Acquisition of Understanding and Skill in Relation to Subjects' Preparation and Meaningfulness of Instruction. James C. Greeno (University of Michigan, Department of Psychology, 330 Packard Road, Ann Arbor, Michigan 48104), Richard E. Mayer, and $C$. Christian StichI. 